\title{
Demonstration of a Stabilized Alumina/Ethanol Colloidal Dispersion Technique for Seeding High Temperature Air Flows
}

Mark P. Wernet

Lewis Research Center

Cleveland, Ohio

Gary J. Skoch

Vehicle Propulsion Directorate

U.S. Army Research Laboratory

Lewis Research Center

Cleveland, Ohio

Judith $\mathrm{H}$. Wernet

Case Western Reserve University

Cleveland, Ohio

Prepared for the

16th International Congress on Instrumentation for Aerospace Simulation Facilities sponsored by the Institute of Electrical and Electronics Engineers

Dayton, Ohio, July 18-21, 1995 


\title{
Demonstration of a Stabilized Alumina/Ethanol Colloidal Dispersion Technique for Seeding High Temperature Air Flows
}

\author{
Mark P. Wernet \\ National Aeronautics and Space Administration \\ Lewis Research Center \\ Cleveland, $\mathrm{OH}$
}

\author{
Gary J. Skoch \\ ARL Vehicle Propulsion Directorate \\ Lewis Research Center \\ Cleveland, $\mathrm{OH}$
}

\author{
Judith H. Wernet \\ Case Western Reserve University \\ Cleveland, $\mathrm{OH}$
}

\begin{abstract}
Laser anemometry enables the measurement of complex flow fields via the light scattered from small particles entrained in the flow. In the study of turbomachinery, refractory seed materials are required for seeding the flow due to the high temperatures encountered. In this work we present a $\mathrm{pH}$ stabilization technique commonly employed in ceramic processing to obtain stable dispersions for generating aerosols of refractory seed material. By adding submicron alumina particles to a preadjusted $\mathrm{pH}$ solution of ethanol, a stable dispersion is obtained which when atomized, produces a high quality aerosol. Commercial grade alumina powder is used with a moderate size distribution. Other metal oxide powders in various polar solvents could also be used once the point of zero charge $\left(\mathrm{pH}_{\mathrm{pzc}}\right)$ of the powder in the solvent has been determined. Laser anemometry measurements obtained using the new seeding technique are compared to measurements obtained using Polystyrene Latex (PSL) spheres as the seed material.
\end{abstract}

\section{INTRODUCTION}

Laser Doppler Velocimetry (LDV) and Particle Image Velocimetry (PIV) are non-intrusive optical diagnostic techniques for measuring fluid velocities which require seed material to be entrained in the fluid to enable the measurements [1]. Various materials are available for seeding fluid flows; the particular choice of seed material depends on the fluid properties and flow regime under study [2]. The techniques for dispersing and introducing the seed material into the flow are also widely diverse [3] and again are highly dependent on the particular application. In this work we describe the atomization of a dispersion of alumina in ethanol to seed high temperature air flows typically encountered in centrifugal compressors [4].

Subsonic and transonic air flows are of particular interest in aerodynamic component testing. In such flow regimes, shock waves may be present and high temperatures are not uncommon. The presence of shock waves places restrictions on the size and density of useful seed material. Small particle size and low specific gravity are desired to ensure that the particles accurately follow accelerations and decelerations in the flow. The high temperature environment requires a refractory seed material which will not degrade, melt, or agglomerate.

Polystyrene latex (PSL) spheres are a popular seeding material with a specific gravity of 1.05 . PSL spheres are relatively easy to manufacture in large quantities to any size in the range of 0.3 to $10 \mu \mathrm{m}$ [5]. PSL spheres are typically diluted to $\sim 1 \mathrm{wt} \%$ in ethanol and introduced into the air flow upstream of the measurement station via an atomizer/spray nozzle. The ethanol quickly evaporates leaving the PSL particles as a well dispersed aerosol which then travels into the measurement section of the facility. A drawback of PSL is its relatively low melting point of $250^{\circ} \mathrm{C}$. Even before the melting point is reached, the particle surface may become sticky and cause additional agglomeration, or may coat the facility optical access ports.

Another seeding alternative is to generate an aerosol of dry metal oxide powder. Both fluidized beds and cyclone separators have been used to generate aerosols. Dry metal oxide powders are typically agglomerated when they arrive from the manufacturer. The agglomerates must either be broken apart or removed from the aerosol. Although 
both of these seed generators have provisions for eliminating the agglomerates, the seed material may still reagglomerate once inside the delivery system to the facility because the attractive interparticle forces have not been eliminated and can still cause agglomeration. Moisture in the delivered powder or in the air flow further increases the amount of agglomeration. The agglomerated particles result in polydisperse and/or larger particle size distributions than in the original dry powder [3].

Theoretically, one could disperse a refractory metal oxide material in a liquid and atomize the dispersion into the facility as previously discussed for PSL. This technique would have the advantages of the refractory seed material and generation of the aerosol within the facility. However, previous attempts to use a dispersion of aluminum silicate clay particles in ethanol have proved unsuccessful [5]. The particles agglomerated in the liquid due to the interparticle forces and then gravity settled out of solution. Failure to recognize and control the forces led to these previous unsuccessful attempts. The authors in reference 4 identified the interparticle forces acting in a alumina/ethanol dispersion and determined the physical conditions that result in a dispersion stable against agglomeration for effective use as a seeding material. In addition, they also discussed the requirements for a $\mathrm{pH}$ stabilized alumina/ $\mathrm{H}_{2} \mathrm{O}$ system.

The dispersion stabilization technique employed here involves preadjusting the $\mathrm{pH}$ of ethanol far from the point of zero charge $\left(\mathrm{pH}_{\mathrm{pzc}}\right)$ for alumina in ethanol. On subsequent addition of alumina, a stable dispersion can be achieved for use in seeding laser anemometry flow fields. The stabilization technique is not restricted to alumina/ethanol systems. However, for each new metal oxide/solvent system the $\mathrm{pH}_{\mathrm{pzc}}$ of the metal oxide in the solvent must be determined so that the conditions for a stable dispersion are known. The details of this process are discussed in reference 4 , where the authors also demonstrate the stability of the dispersion and verify that no particle agglomeration occurs in the atomization process. In addition, we will discuss in this paper the requirements for an alumina/ $\mathrm{H}_{2} \mathrm{O}$ dispersion.

Laser anemometry measurements obtained from a 4:1 centrifugal compressor facility using the new seeding technique are compared to measurements obtained using PSL seed material. The results show that the alumina aerosol provides a good source of scattering sites in the centrifugal compressor facility.

\section{STABILIZED DISPERSIONS}

When a system of particles is dispersed in a polar liquid (aqueous or nonaqueous) an electrostatic double layer develops around each particle. The generally accepted Stern modification of the GouyChapmann double layer model postulates the formation of counter ions (inert electrolyte ions having the opposite charge of the surface charge strongly adsorbed to the surface) and a diffuse layer where the counter ion concentration decreases as the distance from the surface increases [6].

The stability of a suspension depends on the sign and magnitude of the total energy of interaction between particles. This interaction incorporates the sum of attractive and repulsive force contributions. The attractive forces are always present due to the tendency of the particles to be in contact with each other via London-van der Waals forces. In the alumina/ethanol system, the repulsive force is due to electrostatic repulsion which results from the development of an electrical double layer around each particle upon dispersing the powder into a polar liquid. The electrical double layer produces a repulsive force which is inversely proportional to the separation between particles. A stable suspension is achieved when the repulsive forces are strong enough to overcome the attractive London-van der Waals forces.

Particles become electrically charged by ionization of the surface groups. If the surface contains acidic groups, their dissociation results in a negatively charged surface. Conversely a basic surface takes on a positive charge upon dissociation. In both cases the magnitude of the surface charge depends on the acidic or basic strengths of the surface groups and on the $\mathrm{pH}$ of the solution. By either decreasing or increasing the $\mathrm{pH}$, the surface ionization is suppressed and the surface charge can be reduced to zero at the point of zero charge $\left(\mathrm{pH}_{\mathrm{pzc}}\right)$. Several important changes occur in the properties of metal oxides at their $\mathrm{pH}_{\mathrm{pzc}}$ 's, such as the flocculation of the suspension. At the $\mathrm{pH}_{\mathrm{pzc}}$ the interaction between particles is mainly attractive in the absence of any electrostatic repulsion generated by the surface charge, and therefore the dispersion agglomerates. Determination of the surface charge can be accomplished by using standard titration techniques $[7,8]$.

Hydrous oxide surfaces such as alumina exhibit amphoteric behavior. Both positively and negatively charged surfaces can be obtained by varying the $\mathrm{pH}$ 
or via association and dissociation of surface acid/base groups. Therefore, by adding acid or base to the suspension, the surface charge of the particles can be altered. When the concentration of the potential determining ion (the proton) is changed, the relative adsorption of ions on the surface varies. When the number of positively charged sites and the number of negatively charged sites are equal, the surface charge is reduced to zero. Varying the concentration of counter ions effects the diffuse double layer. Increasing concentrations of counter ions reduces the thickness of the double layer. The surface charge is a function of $\mathrm{pH}$, the concentration of other specifically adsorbed ions and the ionic strength of the suspension. The technique of using $\mathrm{pH}$ to control interparticle forces and stabilize or induce flocculation in dispersions is frequently used in ceramic processing to control the stability of powder slurries to provide improved green ceramic uniformity. Some aspects of colloidal processing require repulsive forces, whereas others require attractive forces.

\section{DISPERSION PREPARATION}

The $\alpha$-alumina powder used in this work was commercial grade high purity (>99.99\%) AKP-15 obtained from Sumitomo Chemical Company. The powder has a specific gravity of 3.96 and is relatively monodisperse with a mean particle size of $0.7 \pm 0.2$ $\mu \mathrm{m}$. The powder is prepared by a precipitation separation technique that minimizes the number of larger particles which tend to be plate-like. The smaller alumina particles tend to be nearly spherical. Figure 1 shows a SEM photograph of the AKP-15 powder at a magnification of $\times 8500$. Some of the larger particles do appear to be plate-like; however the majority of the particles are small and nearly spherical. Hence this prepared alumina powder should be a good candidate for seed material in laser velocimetry studies.

The ethanol used was $100 \%$ ethanol. The residual water present in $95 \%$ ethanol significantly increases the amount of $\mathrm{HCl}$ required to adjust the $\mathrm{pH}$. The $\mathrm{pH}$ was adjusted with standardized analytical grade $\mathrm{HCl}$ solutions $(1 \mathrm{~N})$

For particulate/solvent systems other than those discussed here, instead of determining the $\mathrm{pH}_{\mathrm{pzc}}$ via the titration technique referenced above, an approximate estimate of the $\mathrm{pH}_{\mathrm{pzc}}$ can be obtained by performing a series of sedimentation tests [4]. A series of $\mathrm{pH}$ solvent solutions are prepared over the range $\mathrm{pH} 1$ to 14 in 1 or $2 \mathrm{pH}$ unit increments. The particles are dispersed in each of the prepared solvents and then allowed to stand in a graduated cylinder. The dispersion which settle the fastest are the ones with a $\mathrm{pH}$ closest to the $\mathrm{pH}_{\mathrm{pzc}}$. A stable dispersion is then obtained by adjusting the solution $\mathrm{pH}$ far away from the identified $\mathrm{pH}_{\mathrm{pzc}}$.

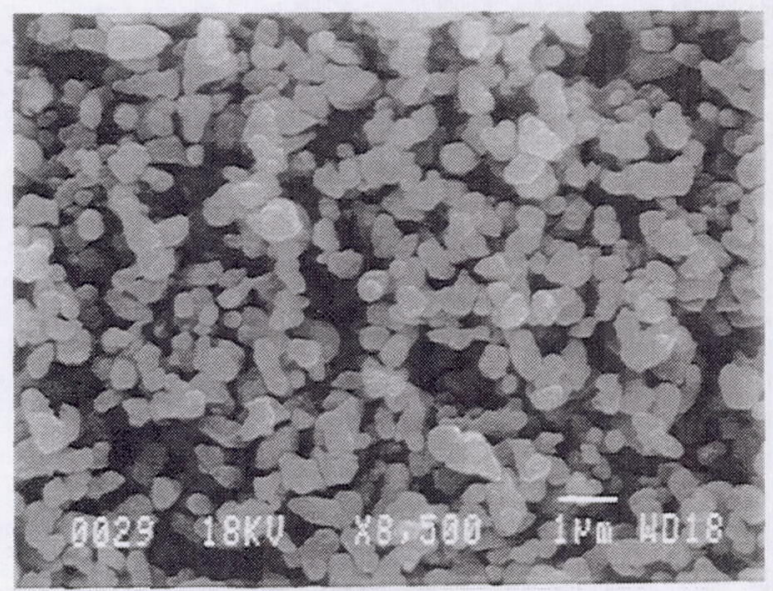

Figure 1: SEM photograph showing the as received alumina powder at a magnification of $\times 8500$.

The equipment required for $\mathrm{pH}$ stabilization of a dispersion of alumina in ethanol or water are: 1) balance; 2) $\mathrm{pH}$ meter (preferably with a calomel electrode for ethanol); 3) Reference buffer solutions; 4) Ultrasonic horn; 5) High purity metal oxide powder; 6) $1 \mathrm{~N}$ solution of $\mathrm{HCl}$; 7) Deionized water or $100 \%$ ethanol; 8) $100 \mathrm{ml}$ beaker. The required weight percent of solids to disperse in a specific volume of solvent depends on the intended application and the acceptable seed particle concentration. The maximum weight percent (wt\%) that has been used by the authors is $20 \mathrm{wt} \%$. Typically a high weight percent dispersion is made initially, which makes dispersing the solids easier since the ultrasonic horn is processing a smaller volume of material, and then diluted to the intended concentration for the application. The choice of solvents depends on the temperature of the application. Ethanol evaporates quicker than water at room temperature. For operating temperatures over $100^{\circ} \mathrm{C}$ the water should evaporate quickly when the dispersion is atomized. The lower explosion limit (LEL) for ethanol is $3.3 \%$ [9].

The following discussion pertains only to the alumina powder obtained from Sumitomo Chemical. Other metal oxide powders or alumina obtained from a different manufacturer will have a different $\mathrm{pH}_{\mathrm{pzc}}$ 
which must be predetermined. The procedure for determining the weight percent of the solids in the volume of solvent is given by:

$$
\text { Alumina wt } \%=\frac{\mathrm{m}_{\mathrm{Al}_{2} \mathrm{O}_{3}}}{\mathrm{~m}_{\mathrm{Al}_{2} \mathrm{O}_{3}}+\rho_{\mathrm{s}} \cdot \mathrm{v}_{\mathrm{s}}}
$$

where $\mathrm{m}_{\mathrm{Al}_{2} \mathrm{O}_{3}}$ is the mass of solid, $\rho_{\mathrm{s}}$ is the density of the solvent, and $\mathrm{v}_{\mathrm{s}}$ is the volume of solvent. For example, to achieve a $10 \mathrm{wt} \%$ dispersion of $\mathrm{Al}_{2} \mathrm{O}_{3}$ in $50 \mathrm{ml}$ of ethanol $\left(\rho_{\text {ethanol }}=0.789 \mathrm{~g} / \mathrm{ml}\right)$ :

$$
\mathrm{m}_{\mathrm{Al}_{2} \mathrm{O}_{3}}=4.4 \mathrm{~g}
$$

After calculating and weighing out the requisite mass of powder, break up any large agglomerated particles in the powder with a spatula.

Next the solution $\mathrm{pH}$ must be adjusted before adding the weighed powder. The $\mathrm{pH}$ of the water must be adjusted in the range of $\mathrm{pH} 1-\mathrm{pH} 5$ in order to obtain a stable dispersion of the $\mathrm{Al}_{2} \mathrm{O}_{3}$. For ethanol dispersions, the $\mathrm{pH}$ must be adjusted to $\mathrm{pH} 1$. A 1 Normal $\mathrm{HCl}$ solution is used to adjust the solvent $\mathrm{pH}$. A 1 Normal solution of $\mathrm{HCl}$ is equivalent to a 1 Molar solution since $\mathrm{HCl}$ has an equivalence of 1 . Dispense $50 \mathrm{ml}$ of high purity deionized water into a $100 \mathrm{ml}$ beaker. Place the $\mathrm{pH}$ electrode in the solution and wait for a constant $\mathrm{pH}$ reading. Add the $1 \mathrm{~N} \mathrm{HCl}$ solution drop wise to the beaker and stir. Check pH level and continue to add acid solution until the desired $\mathrm{pH}$ is obtained.

A word of caution is required on the measured $\mathrm{pH}$ values in ethanol. The definition of $\mathrm{pH}$ is: $\mathrm{pH}=-$ $\log _{10}\left\{\left[\mathrm{H}^{+}\right] \cdot \gamma\right\}$, where $\gamma$ is the chemical activity of the hydronium ion. The $\mathrm{H}^{+}$ion has a high activity in ethanol (on the order of $\gamma=250$ ). The chemical activity is an indicator of the behavior of a one solvent in another. The $\mathrm{H}^{+}$behaves like a super acid, which means that the measured $\mathrm{pH}$ level is the true hydronium ion concentration multiplied by the activity. Hence, a measured $\mathrm{pH} 1$ solution of $\mathrm{HCl}$ in ethanol is actually only a true $\mathrm{pH} 3.4$ level concentration of $\mathrm{H}^{+}$. In addition, the activity of the $\mathrm{H}^{+}$is affected by the purity of the ethanol. The activity drops to $\gamma=0.6$ in a $50: 50$ ethanol water mixture, which means the measured $\mathrm{pH}$ only differs from the true $\mathrm{pH}$ by $0.21 \mathrm{pH}$ units. The shift in activity is very non-linear and decreases very rapidly as the water concentration in ethanol increases from zero. Therefore, only $100 \%$ ethanol is recommended for creating alumina/ethanol dispersions, since only a few milliliters of $1 \mathrm{~N} \mathrm{HCl}$ are required to shift an off the shelf $\mathrm{pH} 7,1$ gal bottle of ethanol to a $\mathrm{pH}$ of 1 .

Now the weighed powder is added to the $\mathrm{pH}$ adjusted solvent and stirred. The ultrasonic horn (sonicator) is used to break up the remaining agglomerates in the powder. A Heat Systems Model 2020 sonicator was used in our studies. The sonicator is rated at 575 Watts, with the $1 / 2$ inch transducer. The sonicator was operated at $50 \%$ of full power with a 1 second on/1 second off duty cycle for a period of 3 to 5 minutes. The transducer is immersed in the dispersion approximately $1-2 \mathrm{~cm}$ from the bottom of the beaker. The beaker is moved around under the transducer while in operation to ensure that agglomerated particles are not merely pushed aside by the ultrasonic field to the edges of the beaker. A high aspect ratio (height/diameter) vessel is best for sonication since the settled agglomerated particles are always located under the transducer. After sonicating the dispersion it is ready to be diluted to the desired wt\% and/or placed into the atomizer for generating an aerosol. The diluting solution must have also been preadjusted to $\mathrm{pH} 1$ prior to adding the concentrated alumina dispersion. When these steps are followed, the alumina/water and alumina/ethanol dispersions created using the alumina from Sumitomo Chemical are stable for over $24 \mathrm{hrs}$ [4].

\section{CENTRIFUGAL COMPRESSOR}

The compressor used as the testbed for the new seeding technique, is a $4.5 \mathrm{~kg} / \mathrm{sec}, 4: 1$ pressure ratio centrifugal compressor. The impeller has 15 main blades and 15 splitter blades with $50^{\circ}$ of back-sweep at the exit. The design rotational speed is $21789 \mathrm{rpm}$, which results in a maximum blade passing frequency of $10.9 \mathrm{kHz}$ in the splitter region. Blade heights range from $64 \mathrm{~mm}$ at the inlet to $17 \mathrm{~mm}$ at the exit. The inlet and exit tip diameters are $210 \mathrm{~mm}$ and $431 \mathrm{~mm}$, respectively. The impeller is being tested with a vaneless diffuser in order to duplicate the environment that was used in a $3-D$ steady viscous code analysis.

Optical access is provided by windows placed at 16 locations along the compressor flow path. The window surfaces were kept flat in order to prevent optical distortion of the laser beams passing through them. Several very small windows were used in order to keep deviations from the true shroud contour, caused by the flat window surface, to a minimum as 
well. Circular windows are used in areas where shroud curvature is high and range in size from 14 to $23 \mathrm{~mm}$ in diameter. Rectangular windows are used upstream of the impeller and circular arc windows are used downstream. These windows can be slightly larger because there is less shroud curvature in either the streamwise or circumferential directions, or both. The window shapes and dimensions that were selected result in maximum mismatch of 203 to 381 $\mu \mathrm{m}$ between the window surfaces and the true shroud contour.

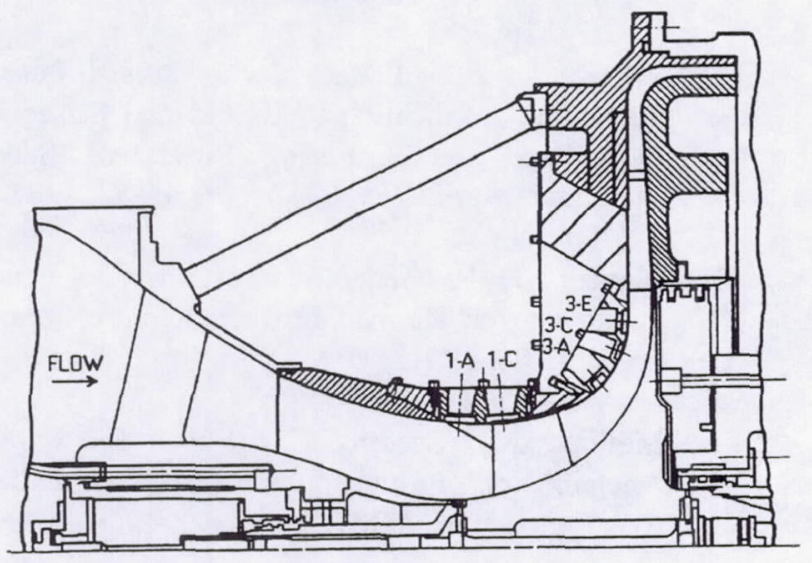

Figure 2: Schematic layout of centrifugal compressor facility showing one configuration of window inserts.

The sixteen individual windows are epoxied into eight window frames that are then installed along the compressor flow path in pairs. Each frame contains from one to three separate windows, so that a particular pair of frames will provide optical access to anywhere from three to five locations along the flow path. Several combinations of window frame pairs are required in order to obtain access to all 16 measurement stations. Figure 2 shows one combination that contains a total of five windows labeled 1-A, 1-C, 3-A, 3-C, and 3-E.

\section{LASER ANEMOMETER}

A single component LDV system was constructed for obtaining velocity measurements in the centrifugal compressor facility. A 4 watt argon ion laser operating at $514.5 \mathrm{~nm}$ was used to generate a $90 \mu \mathrm{m}$ diameter probe volume with $6.3 \mu \mathrm{m}$ fringes. A 160 $\mathrm{mm}$ focal length $\mathrm{f} / 3$ collection lens was used in a direct backscatter arrangement. The beam separation prism was mounted to a computer controlled rotation stage so that the angle of the fringes can be changed. Velocity measurements were recorded at 3 angular orientations at each measurement station. The fringe angles were oriented at $0^{\circ}$ and $\pm 15^{\circ}$ to the estimated true flow angle. The velocity vector magnitude and flow angle are determined from a least squares fit of the 3 different fringe angle measurements to a cosine function.

A shaft angle encoder and buffer interface were used to record the rotor angular position for each realized velocity measurement. The rotor was divided into 3000 bins per revolution, or 200 bins per main blade passage. Data from the entire circumference of the rotor were ensemble averaged into a single 200 bin blade passage.

\section{RESULTS AND DISCUSSION}

The LDV was used to perform spanwise surveys near the blade tip region where the flow exhibits the greatest pitchwise variation in velocity. Both $0.6 \mu \mathrm{m}$ diameter PSL and the AKP-15 alumina powder were used at identical compressor operating conditions. The comparison measurements were taken through casing window 3-A shown in figure 2, which corresponds to $71 \%$ chord. At this chord location the temperature has not exceeded the PSL melting temperature. Previous experience has shown that at higher percent chord positions the PSL begins to coat the windows with an optically diffusive coating. In addition, the PSL usually leaves powdery deposits on the windows near the entrance to the impeller. Usually, the alumina seed did not leave any appreciable coating on the windows. The survey positions covered the range of 90 to $65 \%$ span in $5 \%$ span increments, which contains the effects of the blade tip clearance flow. The tip clearance flow, with its large velocity gradient, should be a good test of the fidelity of the alumina tracer particles.

The results from three measurements stations ( 90 , $75,60 \%$ span) are shown in figure 3 through 5 . Each plot contains a comparison of the two different seed particle measurements $(\mathrm{PSL}=$ solid line, alumina $=$ dotted line), showing the computed absolute velocity vector magnitude, flow angle and cumulative number of measurements from all three fringe angle orientations at each measurement station. The blade rotation is from right to left, and the main blade is the leftmost blade followed by the splitter blade. The effective blade positions are indicated by the vertical lines in the number of measurements plots. The effects of the tip clearance flow are evident in figures 3 and 4 , where the low momentum leakage flow is observed on the pressure side of the blades. 
In general, the measurements obtained via the alumina seed agree very well with those obtained using PSL. The PSL particles show a slightly higher flow following fidelity indicated by the steeper slopes in the velocity measurements in the presence of flow accelerations/decelerations. The higher specific gravity alumina particles still do appear to adequately follow the changes in the complex compressor flow. The main distinction appears to be in the distribution of the seed material across the blade passage as indicated by the number of measurements. Neither seed material was uniformly distributed across the blade passage. The PSL particles were generally distributed closer to the suction surface of the blades than the alumina. There was a tendency of the alumina particles to 'build up' on the pressure side of the blades as indicated in the number of measurements plots. This effect is most noticeable in figure 5 , for the $60 \%$ span measurement station. Hence, measurements were not obtained near the suction surface of the blades using the alumina seed.

\section{CONCLUSIONS}

A novel technique for generating high quality refractory aerosols for use in laser anemometry/particle image velocimetry studies has been presented. The ability to generate high quality aerosols of metal oxide powders has many potential applications in high temperature air flow studies. The seed generation scheme employs techniques for stabilizing dispersions typically used in ceramic processing. The refractory powder used in this study was selected due to the easy availability of the material from a commercial supplier in the desired particle size range. Other lower specific gravity metal oxides may easily be substituted for alumina once a suitable source for the material can be identified. In all cases the metal oxide powder must be characterized to determine the $\mathrm{pH}_{\mathrm{pzc}}$ for the powder/solvent combination. The preparation of the powder affects the $\mathrm{pH}_{\mathrm{pzc}}$, hence, even the same metal oxide from different manufacturers may have widely differing $\mathrm{pH}_{\mathrm{pzc}} \mathrm{S}$.

LDV measurements obtained in a centrifugal compressor via an alumina/ethanol dispersion agreed favorable with those obtained using PSL. As expected, the higher specific gravity alumina particles lagged behind the flow accelerations/decelerations to a greater extent than the PSL particles. However, the deviations between the measurements were not so significant as to disqualify the value of the alumina measurements. The refractory alumina particles can withstand the higher temperatures encountered further back in the centrifugal compressor where the PSL material degrades and becomes unusable. Hence, we feel that the slight loss of flow following fidelity is acceptable when the alternative is to not obtain measurements at all.

\section{REFERENCES}

[1] Adrian, R. J. and Yao, C. S.,"Pulsed Laser Technique Application to Liquid and Gaseous Flows and the Scattering Power of Seed Materials", Appl. Opt. vol. 24, pp. 44-52, 1985.

[2] Meyers, J. F., "Generation of Particles and Seeding", von Karman Institute Lecture Series pp. 1991-08, 1991.

[3] Melling, A., "Seeding Gas Flows for Laser Anemometry", Propulsion and Energetics Panel $67^{\text {th }}$ Symposium, AGARD-CP-399, 1986.

[4] Wernet, J. H. and Wernet, M. P., "Stabilized Alumina/Ethanol Colloidal Dispersion for Seeding High Temperature Air Flows", Proceedings of the ASME Symposium on Laser Anemometry: Advances and Applications, Lake Tahoe, NV, June 19-23, 1994.

[5] Nichols, C. E., Jr., "Preparation of Polystyrene Microspheres for Laser Velocimetry in Wind Tunnels", NASA TM-89163, 1987.

[6] Moreno, R., "The Role of Slip Additives in Tape Casting", American Ceramic Society Bulletin, vol. 71, no. 10, pp. 1521-1531, 1992.

[7] Overbeek, J., Colloid Science, vol. 1, ed. H Kruyt, 1952.

[8] Parks, B. and de Bruyn, P., "The Zero Point of Charge of Oxides", J. Phys. Chem., vol. 66, pp. $967,1962$.

[9] Hodgman, C. D., Editor , Handbook of Chemistry and Physics, Chemical Rubber Publishing Company, Cleveland, OH., 1958. 

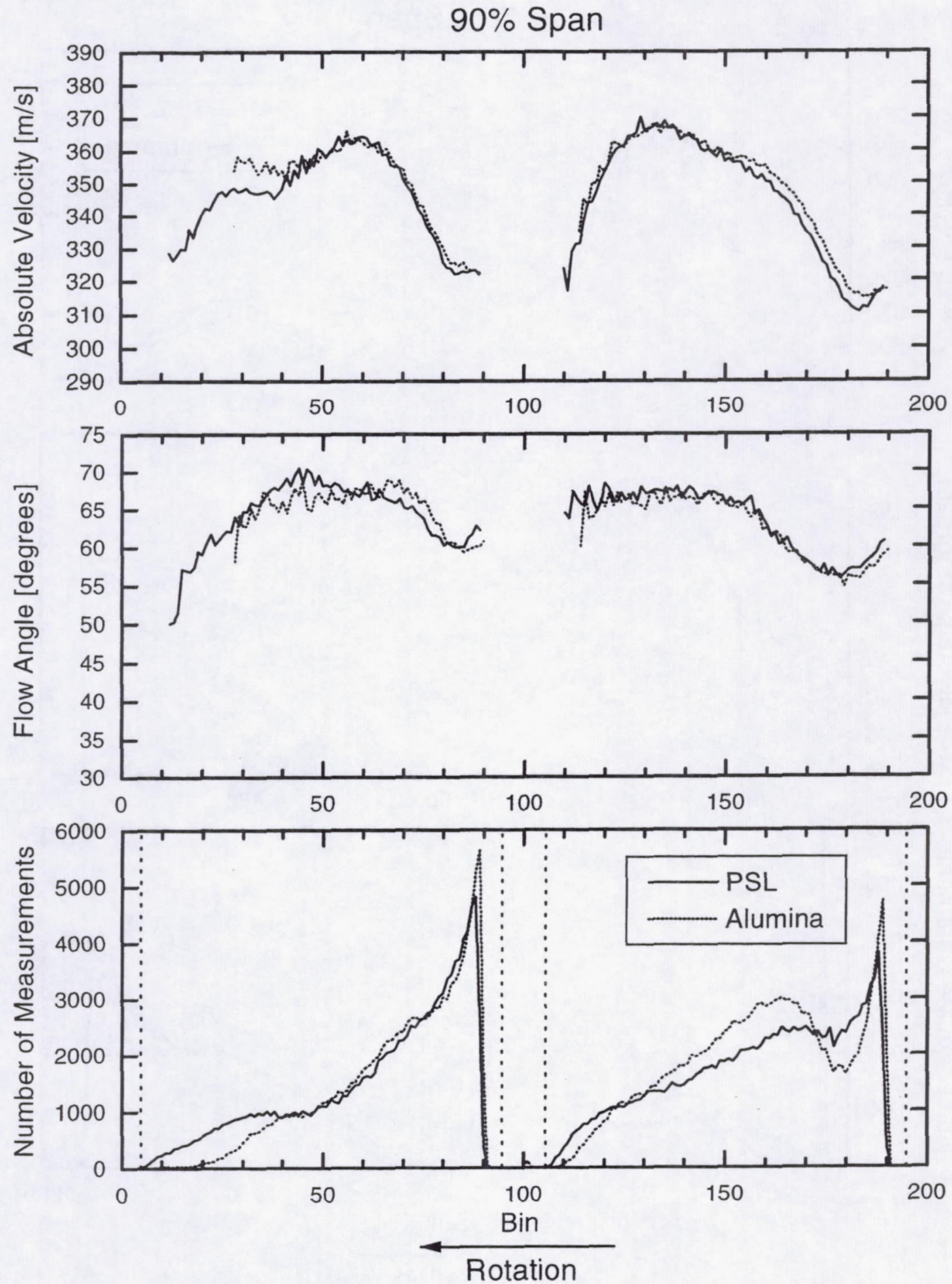

Figure 3: Comparison of LDV measurements obtained using alumina and PSL at 90\% span. The left most vertical dashed line indicates the location of the main blade suction surface. The two vertical lines near bin 100 indicate the pressure and suction surfaces of the splitter blade. The right most vertical line indicates the pressure side of the main blade. 

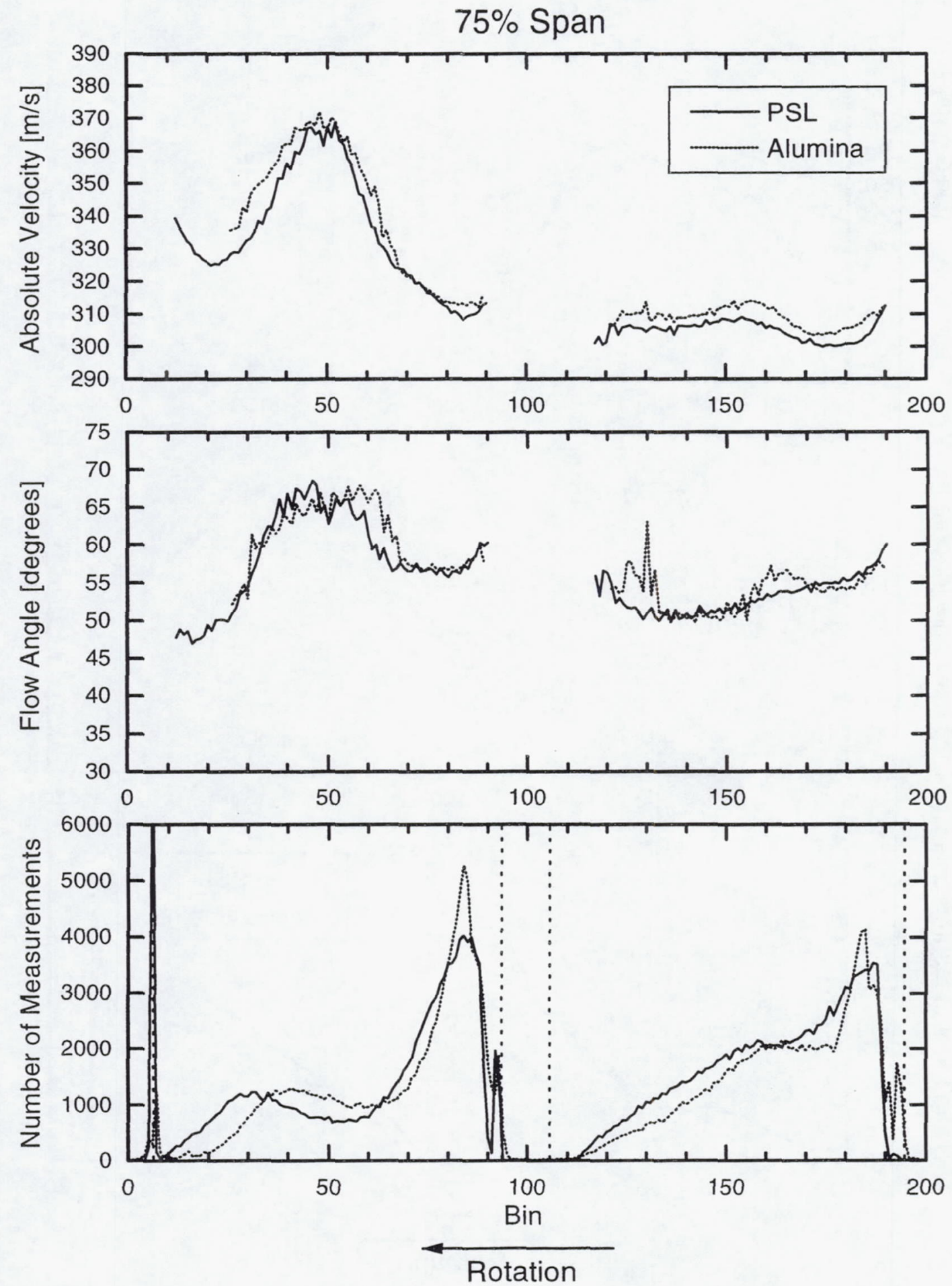

Figure 4: Comparison of LDV measurements obtained using alumina and PSL at 75\% span. The left most vertical dashed line indicates the location of the main blade suction surface. The two vertical lines near bin 100 indicate the pressure and suction surfaces of the splitter blade. The right most vertical line indicates the pressure side of the main blade. 

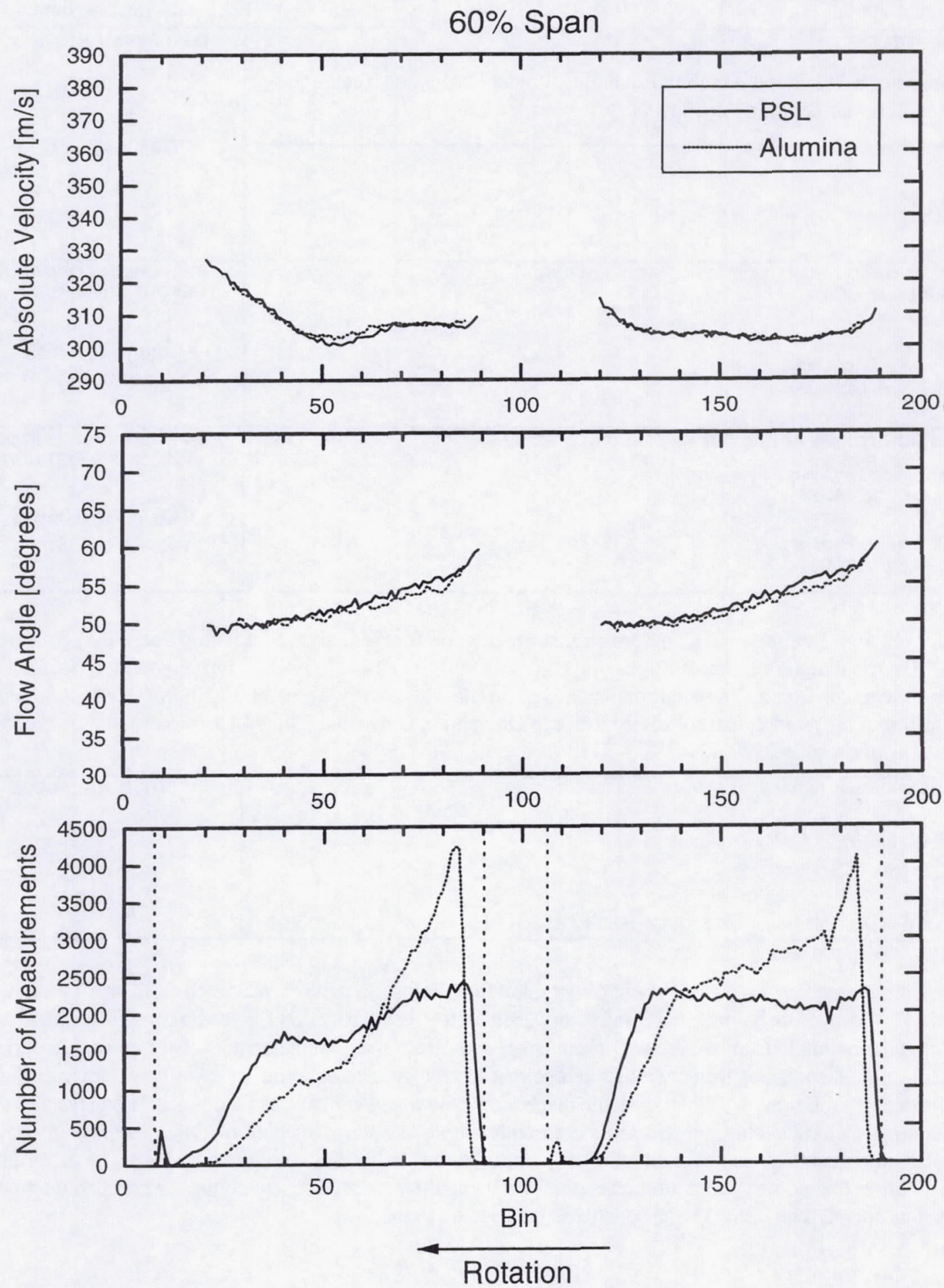

Figure 5: Comparison of LDV measurements obtained using alumina and PSL at 60\% span. The left most vertical dashed line indicates the location of the main blade suction surface. The two vertical lines near bin 100 indicate the pressure and suction surfaces of the splitter blade. The right most vertical line indicates the pressure side of the main blade. 


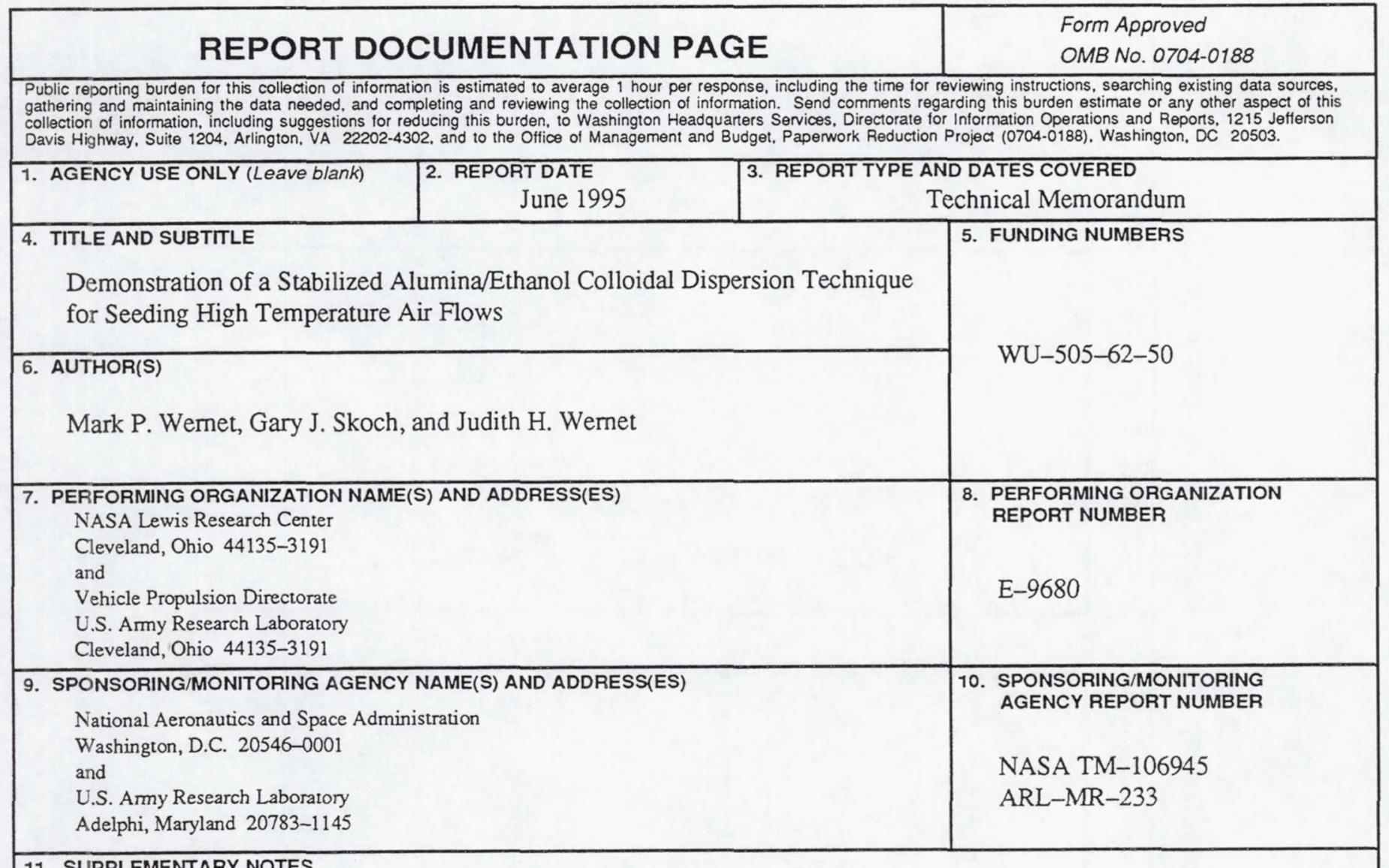

11. SUPPLEMENTARY NOTES

Prepared for the 16th International Congress on Instrumentation for Aerospace Simulation Facilities sponsored by the Institute of Electrical and Electronics Engineers, Dayton, Ohio, July 18-21, 1995. Mark P. Wernet, NASA Lewis Research Center; Gary J. Skoch, Vehicle Propulsion Directorate, U.S. Army Research Laboratory, NASA Lewis Research Center; and Judith H. Wernet, Case Western Reserve University, Cleveland, Ohio 44106. Responsible person, Mark P. Wernet, organization code 2520 , (216) 433-3752.

12a. DISTRIBUTION/AVAILABILITY STATEMENT 12b. DISTRIBUTION CODE

Unclassified - Unlimited

Subject Category 35

This publication is available from the NASA Center for Aerospace Information, (301) 621-0390.

13. ABSTRACT (Maximum 200 words)

Laser anemometry enables the measurement of complex flow fields via the light scattered from small particles entrained in the flow. In the study of turbomachinery, refractory seed materials are required for seeding the flow due to the high temperatures encountered. In this work we present a pH stabilization technique commonly employed in ceramic processing to obtain stable dispersions for generating aerosols of refractory seed material. By adding submicron alumina particles to a preadjusted $\mathrm{pH}$ solution of ethanol, a stable dispersion is obtained which when atomized, produces a high quality aerosol. Commercial grade alumina powder is used with a moderate size distribution. Other metal oxide powders in various polar solvents could also be used once the point of zero charge $\left(\mathrm{pH}_{\mathrm{pzc}}\right)$ of the powder in the solvent has been determined. Laser anemometry measurements obtained using the new seeding technique are compared to measurements obtained using Polystyrene Latex (PSL) spheres as the seed material.

\begin{tabular}{|l|l|l|}
\hline 14. SUBJECT TERMS \\
Particle tracking; Laser velocimetry \\
$\begin{array}{c}\text { 17. SECURITY CLASSIFICATION } \\
\text { OF REPORT } \\
\text { Unclassified }\end{array}$ & $\begin{array}{c}\text { 18. SECURITY CLASSIFICATION } \\
\text { OF THIS PAGE } \\
\text { Unclassified }\end{array}$ & $\begin{array}{c}\text { 19. SECURITY CLASSIFICATION } \\
\text { OF ABSTRACT } \\
\text { Unclassified }\end{array}$ \\
\hline
\end{tabular}



National Aeronautics and

Space Administration

Lewis Research Center

21000 Brookpark Rd.

Cleveland, $\mathrm{OH}$ 44135-3191

Official Business

Penalty for Private Use $\$ 300$

POSTMASTER: If Undeliverable - Do Not Return 